\title{
Chronic thromboembolic pulmonary hypertension: a review
}

Cheryl Zhiya $\underline{\text { Chong }}{ }^{1}$, MBBs, Edgar Lik Wui $\underline{T a y}^{1}$, MBBS, MRCP, Ching Hui Sia ${ }^{1}$, MBBs, Kian Keong $\underline{\text { Poh }}^{1}$, MBBChir, MA

\begin{abstract}
Chronic thromboembolic pulmonary hypertension (CTEPH) is a unique form of pulmonary hypertension resulting from obstruction of the pulmonary artery by fibrotic thromboembolic material, usually initiated by recurrent or incomplete resolution of pulmonary embolism. This distinct form of pulmonary hypertension is classified under Group 4 of the World Health Organization classification. Further investigations are usually initiated, with transthoracic echocardiography followed by right heart catheterisation and pulmonary angiography as the gold standard. Definitive treatment is usually in the form of surgical pulmonary endarterectomy. Inoperable CTEPH is medically treated with pharmacological agents such as phosphodiesterase Type 5 inhibitors, endothelin receptor antagonists, soluble guanylate cyclase stimulators and prostacyclin. Recent developments have made balloon pulmonary angioplasty a viable option as well.
\end{abstract}

Keywords: chronic thromboembolic pulmonary hypertension, pulmonary embolism, pulmonary endarterectomy, pulmonary hypertension, thromboemboli

\section{INTRODUCTION}

Chronic thromboembolic pulmonary hypertension $(\mathrm{CTEPH})$ usually manifests in patients due to recurrent or incomplete resolution of pulmonary embolism (PE). It is caused by the fibrotic transformation of pulmonary artery thromboemboli, resulting in chronic obstruction in the macroscopic pulmonary arteries, as well as vascular remodelling in the microvasculature of the pulmonary system. (1) The true incidence of CTEPH is likely to be underestimated by studies that only follow patients after a $\mathrm{PE},{ }^{(2)}$ but is estimated to be $1 \%-5 \%$ among survivors of acute $P E .^{(3,4)}$

CTEPH could represent the progression of long-standing and unresolved PE. In the early stages of the disease, patients may not have resting pulmonary hypertension (known as chronic thromboembolic disease [CTED]), but often have exercise intolerance. Exercise intolerance associated with exertional chest pain could be attributed to increased dead space ventilation. This is also often related to pulmonary vascular obstruction and hence limitation of maximal cardiac output upon exertion. Thus, in patients with a past medical history of $\mathrm{PE}$, symptoms such as exercise intolerance and exertional chest pain should be evaluated. ${ }^{(5,6)}$

\section{RISK FACTORS}

Risk factors for CTEPH are often related to those of PE (Box 1). In particular, prior deep vein thrombosis (DVT) and PE have been established to be risk factors for CTEPH. ${ }^{(7-9)}$ This is especially important, as CTEPH could be an alternative natural history of a condition in cases where there is limited resolution of thromboemboli and pulmonary artery obstruction leading to pulmonary hypertension (Fig. 1). ${ }^{(7,10)}$

While CTEPH is more likely to develop in patients with a past medical history of PE or DVT, up to $25 \%$ of patients diagnosed with CTEPH do not have a documented history of PE and up to $45 \%$ do not have a history of DVT. ${ }^{(11)}$

\section{PATHOPHYSIOLOGY Clinical features}

Patients who develop CTEPH generally have an asymptomatic or latent phase. They may present with shortness of breath, chest discomfort and increased fatigability. Some patients present late, only when there are signs or symptoms suggestive of right ventricular failure such as peripheral oedema, ascites or syncope. ${ }^{(12)}$

Physical examination findings are those of pulmonary hypertension. These include discernible right ventricular impulse, a split second heart sound with accentuation of the pulmonic component, varying degrees of tricuspid regurgitation and a right ventricular S4 gallop. In advanced stages, there may be signs of right heart failure, including jugular venous distension, peripheral oedema, hepatomegaly, ascites and a right-sided S3 (third heart sound). ${ }^{(13)}$ However, it must also be noted that most physical examination findings may not be unique to CTEPH and are also found in other forms of pulmonary hypertension. Fig. 1 shows the pathophysiology of CTEPH.

\section{Diagnosis}

It should be noted that all patients with pulmonary hypertension should be assessed for CTEPH even in the absence of prior PE. Echocardiography is often the first modality to detect pulmonary hypertension in the evaluation of a breathless patient. Based on the European Society of Cardiology/European Respiratory Society (ESC/ERS) 2015 guidelines for the diagnosis and treatment of pulmonary hypertension, peak tricuspid regurgitation velocity and the presence of other echocardiographic pulmonary hypertension signs (Box 2) help to suggest the probability of 


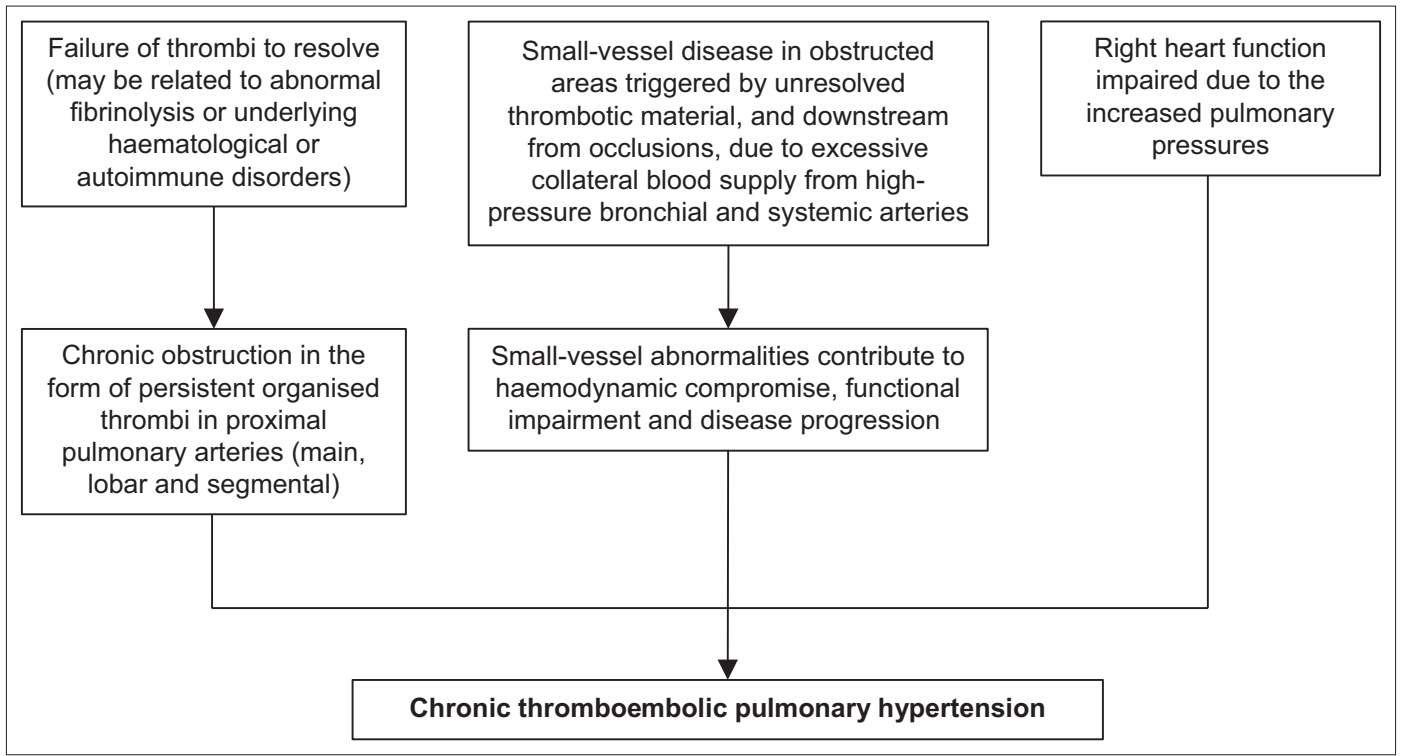

Fig. 1 Diagram shows the pathophysiology of chronic thromboembolic pulmonary hypertension.

Box 1. Risk factors for development of chronic

thromboembolic pulmonary hypertension after acute

pulmonary embolism (PE):

Haemostatic factors

- Elevated levels of factor VIII

- Elevated levels of phospholipid antibodies

- Intrinsic abnormalities in fibrinogen

Medical conditions

- Splenectomy

- Cancer

- Ventriculoatrial shunt

- Chronic inflammatory disease

- Antiphospholipid antibodies

- Hypothyroidism

- Higher pulmonary artery pressures at time of diagnosis of acute PE

Factors related to $\mathrm{PE}$

- Large PE

- Idiopathic aetiology of PE

- Recurrent PE

pulmonary hypertension. Right ventricular function can also be assessed, and the presence of pericardial effusion or an abnormal right atrial size would suggest a poorer prognosis. ${ }^{(14)}$

A ventilation/perfusion (V/Q) lung scan, which has higher sensitivity than conventional computed tomography pulmonary angiography (CTPA), ${ }^{(15)}$ should be performed to diagnose CTED. There are several different published criteria for the diagnosis of pulmonary hypertension based on the degree and extent of mismatch between ventilation and perfusion imaging. However, V/Q scans are not available in most centres. CTPA is commonly used in acute PE, but may be less sensitive in detecting distal disease compared to V/Q scans. Signs of CTEPH seen on CTPA include the presence of dilated pulmonary arteries and right heart chambers. Newer technologies, such as dual-energy CTPA, are increasingly shown to have high sensitivity in the detection of $\mathrm{CTEPH}$. These newer technologies may hence become more commonly used.
Box 2. The European Society of Cardiology/European

Respiratory Society $\mathbf{2 0 1 5}$ guidelines for the diagnosis and treatment of pulmonary hypertension: Ventricles

- Right ventricle/left ventricle basal diameter ratio $>1.0$

- Flattening of interventricular septum

Pulmonary artery

- Right ventricular outflow Doppler acceleration time $<105$ ms

- Mid-systolic notching

- Early diastolic pulmonary regurgitation velocity $>2.2 \mathrm{~m} / \mathrm{s}$

- Pulmonary artery diameter $>25 \mathrm{~mm}$

Inferior vena cava and right atrium

- Inferior cava diameter $>21 \mathrm{~mm}$ with decreased inspiratory collapse

- Right atrial area (end-systole) $>18 \mathrm{~cm}^{2}$

The diagnosis of CTEPH is confirmed with invasive right heart catheterisation and catheter pulmonary angiography. ${ }^{(14)}$ Catheter pulmonary angiography is the current gold standard for assessment of pulmonary vessels. Angiography findings include pulmonary arterial pouching, webs or bands, intimal irregularities, vascular narrowing and obstruction. ${ }^{(16)}$

The diagnosis of CTEPH is based on the following findings obtained after at least three months of effective anticoagulation: (a) mean pulmonary artery pressure (PAP) $\geq 25 \mathrm{mmHg}$, (b) pulmonary artery wedge pressure $\leq 15 \mathrm{mmHg}$ and (c) elevated pulmonary vascular resistance (PVR) $>3$ wood units, confirmed by right heart catheterisation. ${ }^{(17)}$ The diagnostic algorithm for CTEPH is shown in Fig. 2.

\section{Management}

$\mathrm{CTEPH}$ is the only type of pulmonary hypertension that is amenable to surgical treatment and potentially curable. Pulmonary endarterectomy (PEA) is the procedure of choice for $\mathrm{CTEPH}^{(18)}$ offering the best chance of symptomatic and prognostic improvement in eligible patients with excellent long- 


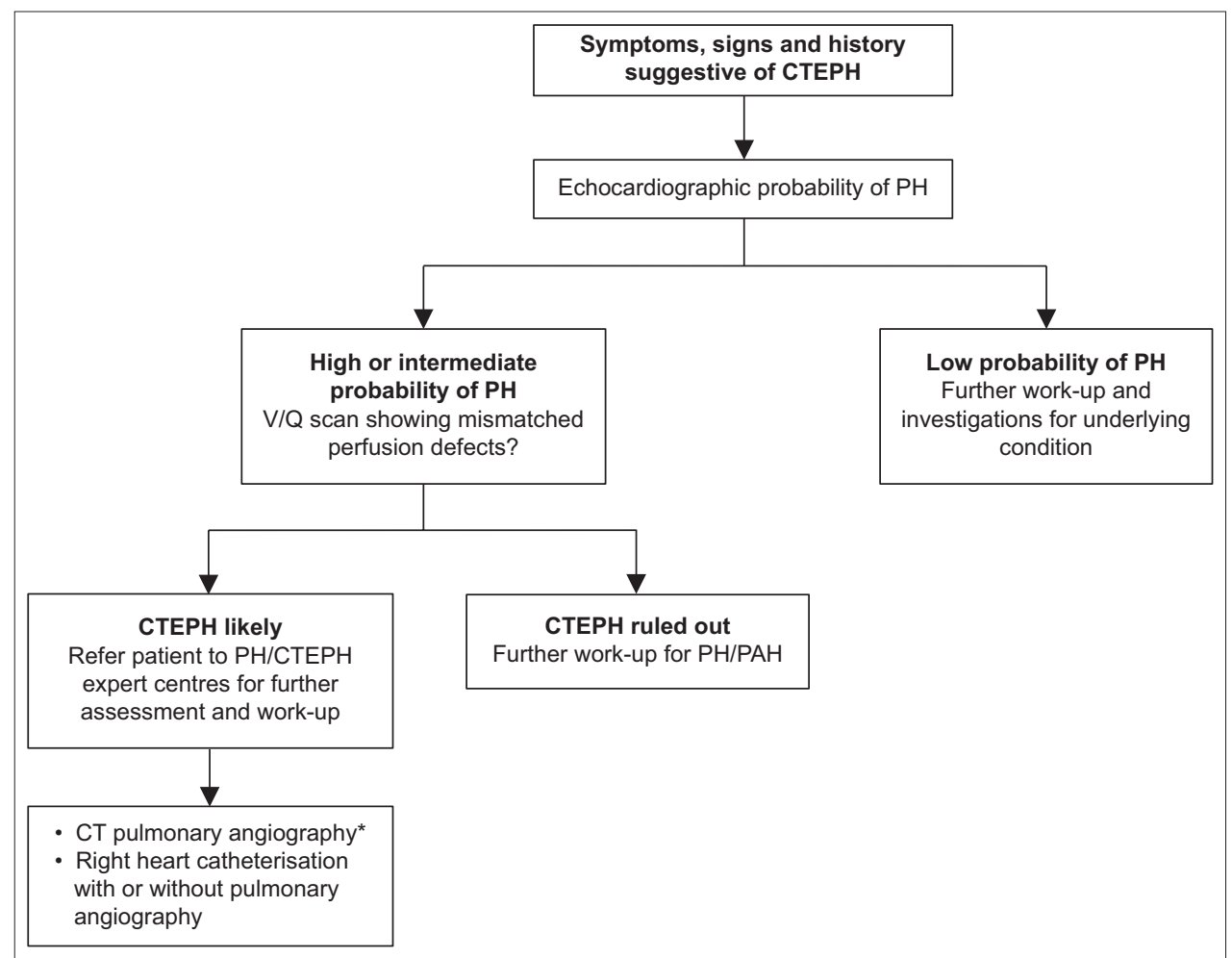

Fig. 2 Flowchart shows the diagnostic algorithm of chronic thromboembolic pulmonary hypertension (CTEPH). ${ }^{*} \mathrm{CT}$ pulmonary angiography alone may miss the diagnosis of chronic thromboembolic pulmonary hypertension. CT: computed tomography; PAH: pulmonary arterial hypertension; PH: pulmonary hypertension; V/Q: ventilation/perfusion (Adapted from 2015 ESC/ERS Guidelines, Fig. 3).

\section{Box 3. Reasons for non-eligibility for surgery:}

\section{Patient factor}

- Age

\section{Comorbidities}

- Severe lung disease

- Conditions affecting the left ventricle of the heart

- Diabetes mellitus

- Hypertension

- Hyperlipidaemia

- Coronary heart disease

- Asthma

- Atrial fibrillation

\section{Anatomical reasons}

- Distal thromboembolism

- Inaccessible thromboembolism

\section{Disease factor}

- Imbalance between peripheral vascular resistance and amount of accessible occlusions

term results in expert centres. ${ }^{(19)}$ The ESC/ERS guidelines ${ }^{(20)}$ also recommend PEA as the treatment of choice for CTEPH patients. The guidelines recognise that operability is multifactorial, and not all patients will be eligible for PEA (Box 3). When assessing the patient's operability, factors such as advanced age, comorbidities, imbalances between increased PVR and the number of accessible occlusions, and poor general condition need to be considered. ${ }^{(21)}$ Operability is dependent on the severity of the symptoms, the anatomy of the disease (how distal lesions are) and pre-existing comorbidities. This is assessed by the CTEPH team, which comprises cardiologists, surgeons, respiratory physicians and anaesthetists. ${ }^{(12)}$ Until recently, PEA remained the only available treatment. However, significant progress has been made in medical treatment and balloon pulmonary angioplasty.

\section{SURGICAL MANAGEMENT: PULMONARY ENDARTERECTOMY \\ Goals}

The main haemodynamic goal is to alleviate right ventricular compromise caused by high PVR. Key respiratory objectives include improving V/Q matching and treating dyspnoea. Treatment is also meant to prevent progressive right ventricular dysfunction and secondary arteriopathy in the remaining patent vessels. ${ }^{(22)}$

\section{Procedure}

PEA involves the removal of organised and incorporated fibrous obstructive tissue from the pulmonary arteries during circulatory arrest under deep hypothermia. After proximal intrapericardial pulmonary artery incision, the correct endarterectomy plane is established and circumferentially followed down to the lobar, segmental, and sometimes subsegmental pulmonary artery branches in each lobe. Completion of the endarterectomy procedure in one lung is usually possible within a 15-20-minute period of deep hypothermic circulatory arrest (providing a bloodless field for visualisation and surgery). This is followed by reperfusion and another period of circulatory arrest for the endarterectomy on the contralateral side. During the rewarming 
Table I. Postoperative complications of PEA.

\begin{tabular}{|ll|}
\hline Complication & Cause \\
\hline Pulmonary haemorrhage & Injury to pulmonary vessels \\
\hline Neurological complications & Brain ischaemia \\
\hline $\begin{array}{l}\text { Persistent pulmonary } \\
\text { artery hypertension }\end{array}$ & - Inadequate endarterectomy \\
\hline Reperfusion oedema & Abrupt normalisation of \\
& $\begin{array}{l}\text { extracellular osmotic pressure in } \\
\text { endarterectomised parts of lung }\end{array}$ \\
\hline
\end{tabular}

period, additional cardiac procedures can be performed after arteriotomy closure if required, depending on the patient's clinical status.

The outcomes with regard to functional status, quality of life, haemodynamics, right ventricular function, and gas exchange make PEA the ideal treatment. After surgery, significant and durable decreases in PAP and PVR are observed in the majority of patients. Cardiac output is increased and right heart function is improved. ${ }^{(23)}$ PEA was also shown to reduce mortality compared to medical management. ${ }^{(24)}$

\section{Preoperative and postoperative concerns}

Preoperative haemodynamic severity and the site of anatomic obstruction are believed to be key predictors of the postoperative outcome of PEA. Patients who benefit from PEA are typically those with fewer distal thrombi, mean PAPs below $38 \mathrm{mmHg}$ and PVR below 425 dynes $/ \mathrm{s} / \mathrm{cm}^{5}$. Mean PAP of $\geq 38 \mathrm{mmHg}$ and PVR $\geq 425$ dynes $/ \mathrm{s} / \mathrm{cm}^{5}$ at reassessment was correlated with worse long-term survival. ${ }^{(25)}$ Outcomes are also worse in patients with distal thrombi. ${ }^{(26)}$

Due to the complications of PEA, mortality rates reported for this procedure range from $4 \%$ to $24 \%$. ${ }^{(23)}$ However, in recent years, in-hospital mortality rates have been less than $5 \%$ for experienced centres with high volumes of PEA cases. ${ }^{(1)}$ Adequate postoperative care is therefore essential. Table I shows the postoperative complications of PEA. ${ }^{(27-29)}$

\section{Persistent pulmonary hypertension after pulmonary endarterectomy}

Almost one-third of patients who undergo PEA may have persistent or residual pulmonary hypertension despite having undergone a successful procedure. ${ }^{(2,30)}$ Persistent pulmonary hypertension can result from incomplete removal of more distal thrombi by inexperienced surgeons, or from concomitant small vessel disease in patients with operable proximal disease. ${ }^{(21)}$ The precise incidence is unclear, as right heart catheterisation is not routinely performed in all patients after PEA. There is also no agreed definition of persistent pulmonary hypertension. This remains the most important cause of early postoperative morbidity and mortality. In the international CTEPH registry, $16.7 \%$ of patients had persistent pulmonary hypertension, and this complication was associated with higher early mortality. ${ }^{(31)}$ Furthermore, persistent/recurrent CTEPH following surgery
Box 4. Complications of balloon pulmonary angioplasty: ${ }^{(38-40)}$ During procedure:

- Vessel dissection

- Vessel rupture

- Contrast extravasation and leakage into bronchi

- Wire injury

After procedure:

- Reperfusion oedema

- Pulmonary artery perforation

- Haemorrhagic pleural effusions

- Haemoptysis

occurs in up to $35 \%$ of patients. There is hence a strong rationale for consideration of targeted therapies, which is supported by the current guidelines. ${ }^{(32)}$ Therapeutic anticoagulation is also important in preventing repeat embolic episodes and recurrence of pulmonary hypertension or $\mathrm{CTEPH}$.

\section{BALLOON PULMONARY ANGIOPLASTY: AN ALTERNATIVE TREATMENT}

Balloon pulmonary angioplasty (BPA) has also emerged recently as a promising treatment modality. ${ }^{(33)}$ It is interventional, involving the insertion of a balloon catheter into pulmonary vessels to dilate pulmonary stenoses. Since 1988, BPA has been performed for patients with $\mathrm{CTEPH}$ who are ineligible for surgical management of PEA. ${ }^{(34)}$

Initial studies showed that BPA could potentially improve haemodynamics and symptoms. BPA, however, was initially associated with high complication rates (Box 4). ${ }^{(35-40)}$ In recent years, Japanese colleges have revolutionised procedural techniques and demonstrated that BPA can be performed with improved safety while preserving good outcomes. ${ }^{(26)}$ One study of 424 BPA sessions in 84 consecutive patients had a five-year survival rate of $98.4 \%$ with no periprocedural death. In $92 \%$ of patients, BPA treatment significantly improved mean PAP, PVR and six-minute walk distance, and improvements persisted throughout the follow-up period. ${ }^{(38)}$

Recent studies done with regard to BPA showed consistently beneficial effects on haemodynamics, symptoms, six-minute walk distance, exercise capacity and right ventricular function. Hence, BPA should be an option for patients with inoperable CTEPH or perhaps hybrid treatment (in combination with PEA) for patients with both proximal and distal vessel disease. ${ }^{(35-37)}$

\section{MEDICAL MANAGEMENT}

An estimated $20 \%-40 \%$ of all CTEPH patients are deemed inoperable. ${ }^{(41)}$ Inoperable patients or those with postintervention pulmonary hypertension are treated with pulmonary hypertension-targeted medical therapy. ${ }^{(35)}$ Medical therapy should be considered in patients with inoperable disease, but should not be a substitute for PEA in appropriate surgical candidates. Standard medical treatment of CTEPH consists of diuretics, oxygen therapy and lifelong anticoagulant therapy. 


\section{Long-term anticoagulation therapy}

Currently, anticoagulation is considered part of standard management for CTEPH. Warfarin is used most frequently. Direct oral anticoagulants (DOACs) such as rivaroxaban, dabigatran and apixaban have been approved for their viability and efficacy in venous thromboembolic disease. The main advantages of DOACs over traditional anticoagulants such as warfarin include a lower overall mortality rate, mainly due to fewer episodes of fatal intracranial bleeding; ${ }^{(36)}$ and the lack of the need for blood monitoring. However, DOACs are not a panacea due to the contraindication in patients with significant renal impairment or obesity. ${ }^{(37)}$

The ideal anticoagulant remains elusive. A study on rivaroxaban proved that it was superior to the combination of unfractionated or low-molecular-weight heparins with warfarin. ${ }^{(42)}$ Other non-randomised studies comparing warfarin to DOACs in patients with $\mathrm{CTEPH}$ showed heterogeneous results. ${ }^{(43-46)}$

Specific medical treatment options for CTEPH include phosphodiesterase Type 5 inhibitors, endothelin receptor antagonists, soluble guanylate cyclase stimulators and prostacyclin. ${ }^{(47)}$ Pulmonary hypertension-targeted therapy should only be prescribed by tertiary centres with CTEPH expertise. Choice of medication depends on cost, availability, safety and the functional class of the patient. At present, medical treatment is recommended for patients who are deemed inoperable, such as patients with PEA, or have persistent pulmonary hypertension after PEA surgery.

Supportive therapy is important as well. Oxygen therapy has been shown to reduce PVR in patients with pulmonary arterial hypertension, but no data suggests any benefits of long-term oxygen therapy in CTEPH. Current guidelines recommend oxygen therapy if arterial oxygen partial pressure is consistently less than $60 \mathrm{mmHg} \cdot{ }^{(45)}$

\section{COMPARISON OF PHARMACOLOGICAL THERAPIES}

The various types of pharmacological therapy for the management of CTEPH are shown and compared in Table II. $27,28,32,36,41,48-56)$

\section{Riociguat}

Currently, riociguat has the strongest evidence of effective medical management specific to CTEPH. ${ }^{(28)}$ Riociguat is a member of a class of drugs known as soluble guanylate cyclase stimulators, which cause vasodilation and other disease-modifying effects such as anti-fibrotic, anti-proliferative and anti-inflammatory activity. ${ }^{(29)}$

\section{Phosphodiesterase Type $\mathbf{5}$ inhibitor: sildenafil}

Sildenafil is still a preferred option for medical therapy. Sildenafil inhibits phosphodiesterase Type 5, an enzyme that metabolises cyclic guanosine monophosphate, thereby enhancing the cyclic guanosine monophosphate-mediated relaxation and growth inhibition of vascular smooth-muscle cells, including those in the lungs. ${ }^{(57)}$

\section{Endothelin receptor antagonists}

The endothelin pathway is involved in the pathology of chronic thrombus reorganisation leading to CTEPH, hence supporting the use of endothelin receptor antagonists in the treatment of CTEPH. ${ }^{(46,58)}$ In the MERIT-1 (Macitentan for the Treatment of Inoperable CTEPH) study, macitentan was shown to significantly improve PVR in patients with inoperable CTEPH and was well tolerated.

\section{Prostacyclin}

CTEPH results from non-resolving pulmonary thromboemboli that are resistant to plasmatic anticoagulation. One possibility is that secondary pulmonary arteriopathy is accompanying major vessel obstruction, making CTEPH a potential target for prostacyclin vasodilator therapy. ${ }^{(48)}$

\section{Sildenafil versus riociguat}

A retrospective study (Table II) supports the benefits of riociguat over sildenafil in treating CTEPH. The replacement of sildenafil with riociguat in patients with inoperable or persistent CTEPH may improve pulmonary haemodynamics and functional capacity. ${ }^{(59)}$ However, riociguat is still not well established to demonstrate improvement in patients who are deteriorating and have inoperable CTEPH. ${ }^{(57)}$

\section{ASIAN PERSPECTIVE AND MANAGEMENT OF CHRONIC THROMBOEMBOLIC PULMONARY HYPERTENSION IN SINGAPORE}

In most Asian countries, CTEPH remains underdiagnosed due to a lack of trained CTEPH physicians/teams and minimal patient awareness of this condition. ${ }^{(60)}$ Limited access to radioisotope V/Q imaging may also contribute to the difficulty in diagnosing CTEPH. ${ }^{(61)}$ There are few publications relating to CTEPH in Asia. The rate of CTEPH in patients with a history of previous PE was estimated to be $14 \%$ in Japan. This is higher than in other published registries. ${ }^{(58)}$ A study in 2017 showed that the crude annual incidence of diagnosed PE and crude annual full (i.e. including both diagnosed and undiagnosed) incidence of CTEPH were 6.7 and 1.9 per 100,000 population in Japan, respectively. ${ }^{(29)}$ There is currently no Asian registry of $\mathrm{CTEPH}$, and we feel that a multicentre registry should be initiated to study this condition in detail and understand if there are interethnic differences in the clinical presentation and response to treatment.

CTEPH patients in Singapore are currently privileged to have access to surgical management (i.e. PEA), BPA and medical management. In terms of medical treatment, riociguat, bosentan, ambrisentan and sildenafil are available to our patients. There is currently a collaboration between the two national heart centres to study patients with pulmonary arterial hypertension, including those with CTEPH, and we hope that this will shed light on this disease and provide better future care for these patients. 
Table II. Comparison of pharmacological therapy for chronic thromboembolic pulmonary hypertension (CTEPH).

\begin{tabular}{|c|c|c|c|}
\hline Drug & Author, yr & Study & Results \\
\hline ERA - macitentan & Ghofrani et al, $2017^{(50)}$ & $\begin{array}{l}\text { Macitentan for the treatment of } \\
\text { inoperable CTEPH (MERIT-1): multicentre, } \\
\text { Phase 2, randomised, double-blind, } \\
\text { placebo-controlled study }\end{array}$ & $\begin{array}{l}\text { Wk 16: geometric mean PVR decreased to } \\
73.0 \% \text { of baseline in the macitentan group and } \\
\text { to } 87.2 \% \text { in the placebo group. }\end{array}$ \\
\hline ERA - bosentan & Jais et al, $2008^{(56)}$ & $\begin{array}{l}\text { Bosentan for treatment of inoperable } \\
\text { CTEPH: BENEFiT (Bosentan Effects } \\
\text { in iNopErable Forms of chronlc } \\
\text { Thromboembolic pulmonary hypertension): } \\
\text { randomised, placebo-controlled trial }\end{array}$ & $\begin{array}{l}\text { Significant treatment effect of bosentan over } \\
\text { placebo on PVR was demonstrated: }-24.1 \% \text { of } \\
\text { baseline. Total pulmonary resistance (TE: }-193 \\
\text { dynes } / \mathrm{s} / \mathrm{cm}^{5} \text { to }-104 \text { dynes } / \mathrm{s} / \mathrm{cm}^{5} \text { ) and cardiac } \\
\text { index }\left(\mathrm{TE}: 0.3 \mathrm{~L} / \mathrm{min} / \mathrm{m}^{2} \text { to } 0.46 \mathrm{~L} / \mathrm{min} / \mathrm{m}^{2} \text { ). }\right. \\
\text { Mean treatment effect on } 6 \mathrm{MWD} \text { was }+2.2 \mathrm{~m} \text {. }\end{array}$ \\
\hline ERA - bosentan & Mitsakis et al, $2017^{(27)}$ & $\begin{array}{l}\text { Effects of ERA bosentan on myocardial } \\
\text { glucose metabolism in PAH and CTEPH }\end{array}$ & $\begin{array}{l}2 \text { NYHA class III patients clinically responded } \\
\text { by } 6 \mathrm{MWD} \text {, NT-proBNP and cardiac } \\
\text { echocardiography. RV/LV uptake ratio decreased } \\
\text { after therapy initiation towards normalisation } \\
\text { with a NT-proBNP decrease and tricuspid annular } \\
\text { plane systolic excursion normalisation. }\end{array}$ \\
\hline ERA - ambrisentan & $\begin{array}{l}\text { Escribano-Subias et al, } \\
\text { 2019(55) }\end{array}$ & $\begin{array}{l}\text { Ambrisentan for treatment of inoperable } \\
\text { CTEPH }\end{array}$ & $\begin{array}{l}\text { Wk 16: mean change from baseline in } 6 \mathrm{MWD} \text { was } \\
28.3 \pm 41.7 \mathrm{~m} \text { with ambrisentan and } 6.8 \pm 67.5 \mathrm{~m} \\
\text { in the placebo group. Geometric mean NT- } \\
\text { proBNP concentration (\% baseline) }=-29.4 \% \text { vs. } \\
+14.1 \% \text {; and mean PVR }=-212.5 \pm 392.8 \text { dynes } / \mathrm{s} / \\
\mathrm{cm}^{5} \text { vs. }-108.5 \pm 51.3 \text { dynes } / \mathrm{s} / \mathrm{cm}^{5} \text {. }\end{array}$ \\
\hline $\begin{array}{l}\text { Phosphodiesterase } \\
\text { Type } 5 \text { inhibitor }\end{array}$ & $\begin{array}{l}\text { Suntharalingam et al, } \\
\text { 2008 }\end{array}$ & $\begin{array}{l}\text { Long-term use of sildenafil in inoperable } \\
\text { CTEPH: double-blind, placebo-controlled } \\
\text { pilot study }\end{array}$ & $\begin{array}{l}17 \text { patients demonstrated significant improvements } \\
\text { in } 6 \mathrm{MWD} \text {, activity and symptom components of } \\
\text { QOL, cardiac index, PVR and NT-proBNP. }\end{array}$ \\
\hline $\begin{array}{l}\text { Soluble guanylate } \\
\text { cyclase stimulators - } \\
\text { riociguat }\end{array}$ & Ghofrani et al, $2010^{(49)}$ & $\begin{array}{l}\text { Riociguat for CTEPH and PAH: a Phase } 2 \\
\text { study: } 12 \text {-week, multicentre, open-label, } \\
\text { uncontrolled Phase } 2 \text { study }\end{array}$ & $\begin{array}{l}\text { Median 6MWD increased in patients with } \\
\text { CTEPH and PAH. PVR was significantly reduced. }\end{array}$ \\
\hline $\begin{array}{l}\text { Soluble guanylate } \\
\text { cyclase stimulators - } \\
\text { riociguat }\end{array}$ & $\begin{array}{l}\text { Ghofrani et al and } \\
\text { CHEST-1 Study Group, } \\
2013^{(53)}\end{array}$ & Riociguat for the treatment of CTEPH & $\begin{array}{l}\text { Riociguat significantly improved exercise capacity } \\
\text { and pulmonary vascular resistance in patients } \\
\text { with CTEPH. } 6 \text { MWD distance increased by a mean } \\
\text { of } 39 \mathrm{~m} \text { in the riociguat group, as compared with } \\
\text { a mean decrease of } 6 \mathrm{~m} \text { in the placebo group. } \\
\text { Riociguat was also associated with significant } \\
\text { improvements in NT-proBNP level }(p<0.001) \text { and } \\
\text { WHO functional class }(p=0.003) \text {. }\end{array}$ \\
\hline $\begin{array}{l}\text { Soluble guanylate } \\
\text { cyclase stimulators- } \\
\text { riociguat }\end{array}$ & $\begin{array}{l}\text { Simonneau et al, } \\
2015^{(54)}\end{array}$ & $\begin{array}{l}\text { Riociguat for the treatment of CTEPH: a } \\
\text { long-term extension study (CHEST-2) }\end{array}$ & $\begin{array}{l}\text { Long-term riociguat had a favourable benefit-risk } \\
\text { profile and apparently showed sustained benefits } \\
\text { in exercise and functional capacity for up to one } \\
\text { year. Improvements in } 6 \text { MWD and WHO functional } \\
\text { class observed in CHEST-1 persisted for up to one } \\
\text { year in CHEST-2. In the observed population at } \\
\text { one year, mean } \pm \text { SD } 6 \text { MWD changed by }+51 \pm \\
62 \mathrm{~m}(\mathrm{n}=172) \text { vs. CHEST-1 baseline }(n=237) \text {, and } \\
\text { WHO functional class improved, stabilised and } \\
\text { worsened in } 47,50 \text { and } 3 \% \text { of patients }(n=176) \text {, } \\
\text { respectively, versus CHEST-1 baseline }(n=236) \text {. }\end{array}$ \\
\hline $\begin{array}{l}\text { Soluble guanylate } \\
\text { cyclase stimulators- } \\
\text { riociguat }\end{array}$ & Halank et al, 2017 $7^{(51)}$ & $\begin{array}{l}\text { Riociguat for PAH and CTEPH: results from } \\
\text { a Phase } 2 \text { long-term extension study }\end{array}$ & $\begin{array}{l}68 \text { patients (inoperable CTEPH, } n=41 ; P A H, n=27 \text { ) } \\
\text { Month } 48: 6 \text { MWD increased from baseline by } 69 \pm \\
105 \mathrm{~m} \text {, WHO functional class improved vs. baseline } \\
\text { in } 50 \% \text { of patients. Starting new PAH treatment } \\
\text { was the most frequent clinical worsening event. }\end{array}$ \\
\hline Prostacyclins & $\begin{array}{l}\text { Skoro-Sajer et al, } \\
2007^{(48)}\end{array}$ & Treprostinil for severe inoperable CTEPH & $\begin{array}{l}\text { Significant improvement in 6MWD (P } 1 / 40.01) \text {, } \\
\text { WHO functional class (P 1/4 0.001), NT-proBNP } \\
\text { plasma levels, cardiac outputs and PVR } \\
\text { after } 19.0 \pm 6.3 \mathrm{mth} \text {. Long-term survival was } \\
\text { significantly better than in controls. }\end{array}$ \\
\hline Prostacyclin & 2021 & $\begin{array}{l}\text { Study to find out if selexipag is effective } \\
\text { and safe in patients with CTEPH when } \\
\text { the disease is inoperable or persistent/ } \\
\text { recurrent after surgery (SELECT) }\end{array}$ & Trial was terminated early due to futility. \\
\hline
\end{tabular}

6MWD: six-minute walk distance; ERA: endothelin receptor antagonist; LV: left ventricle; NT-proBNP: N-terminal-pro hormone B-type natriuretic peptide; NYHA: New York Heart Association; PAH: pulmonary arterial hypertension; PVR: pulmonary vascular resistance; QOL: quality of life; RV: right ventricle; SD: standard deviation; WHO: World Health Organization 


\section{REFERENCES}

1. Jenkins D, Madani M, Fadel E, D'Armini AM, Mayer E. Pulmonary endarterectomy in the management of chronic thromboembolic pulmonary hypertension. Eur Respir Rev 2017; 26. pii:160111.

2. Bonderman D, Skoro-Sajer N, Jakowitsch J, et al. Predictors of outcome in chronic thromboembolic pulmonary hypertension. Circulation 2007; 115:2153-8.

3. Ende-Verhaar YM, Cannegieter SC, Vonk Noordegraaf A, et al. Incidence of chronic thromboembolic pulmonary hypertension after acute pulmonary embolism: a contemporary view of the published literature. Eur Respir J 2017; 49. pii:1601792.

4. Konstantinides SV, Vicaut E, Danays T, et al. Impact of thrombolytic therapy on the long-term outcome of intermediate-risk pulmonary embolism. J Am Coll Cardiol 2017; 69:1536-44

5. Klok FA, van der Hulle T, den Exter PL, et al. The post-PE syndrome: a new concept for chronic complications of pulmonary embolism. Blood Rev 2014 28:221-6.

6. Taboada D, Pepke-Zaba J, Jenkins DP, et al. Outcome of pulmonary endarterectomy in symptomatic chronic thromboembolic disease. Eur Respir 2014; 44:1635-45.

7. Kim NH, Lang IM. Risk factors for chronic thromboembolic pulmonary hypertension. Eur Respir Rev 2012; 21:27-31.

8. Lang IM, Simonneau G, Pepke-Zaba JW, et al. Factors associated with diagnosis and operability of chronic thromboembolic pulmonary hypertension. Thromb Haemost 2013; 110:83-91.

9. Klok FA, Delcroix M, Bogaard HJ. Chronic thromboembolic pulmonary hypertension from the perspective of patients with pulmonary embolism. J Thromb Haemost 2018; 16:1040-51.

10. Elwing JM, Vaidya A, Auger WR. Chronic thromboembolic pulmonary hypertension: an update. Clin Chest Med 2018; 39:605-20.

11. Pepke-Zaba J, Delcroix M, Lang I, et al. Chronic thromboembolic pulmonary hypertension $(\mathrm{CTEPH})$ : results from an international prospective registry. Circulation 2011; 124:1973-81

12. Kim NH, Delcroix M, Jenkins DP, et al. Chronic thromboembolic pulmonary hypertension. J Am Coll Cardiol 2013; 62(25 Suppl):D92-9.

13. Auger WR, Kerr KM, Kim NH, Fedullo PF. Evaluation of patients with chronic thromboembolic pulmonary hypertension for pulmonary endarterectomy. Pulm Circ 2012; 2:155-62

14. Galiè N, Humbert M, Vachiery JL, et al. [2015 ESC/ERS Guidelines for the diagnosis and treatment of pulmonary hypertension]. Kardiol Pol 2015; 73:1127206. Polish.

15. Tunariu N, Gibbs SJ, Win Z, et al. Ventilation-perfusion scintigraphy is more sensitive than multidetector CTPA in detecting chronic thromboembolic pulmonary disease as a treatable cause of pulmonary hypertension. J Nucl Med 2007; 48:680-4.

16. Auger WR, Fedullo PF, Moser KM, Buchbinder M, Peterson KL. Chronic major-vessel thromboembolic pulmonary artery obstruction: appearance a angiography. Radiology 1992; 182:393-8.

17. Velayati $A$, Valerio $M G$, Shen $M$, et al. Update on pulmonary arterial hypertension pharmacotherapy. Postgrad Med 2016; 128:460-73.

18. Fedullo P, Kerr KM, Kim NH, Auger WR. Chronic thromboembolic pulmonary hypertension. Am J Respir Crit Care Med 2011; 183:1605-13.

19. Delcroix M, Lang I, Pepke-Zaba J, et al. Long-term outcome of patients with chronic thromboembolic pulmonary hypertension: results from an international prospective registry. Circulation 2016; 133:859-71.

20. Galiè N, Humbert M, Vachiery J-L, Gibbs S, Lang I, Torbicki A, et al. 2015 ESC/ ERS Guidelines for the diagnosis and treatment of pulmonary hypertension. Rev Esp Cardiol (Engl Ed) 2016; 69:177.

21. Jenkins D. Pulmonary endarterectomy: the potentially curative treatment for patients with chronic thromboembolic pulmonary hypertension. Eur Respir Rev 2015; 24:263-71.

22. Banks DA, Pretorius GV, Kerr KM, Manecke GR. Pulmonary endarterectomy: part II. Operation, anesthetic management, and postoperative care. Semin Cardiothorac Vasc Anesth 2014; 18:331-40.

23. Mayer E, Klepetko W. Techniques and outcomes of pulmonary endarterectomy for chronic thromboembolic pulmonary hypertension. Proc Am Thorac Soc 2006; 3:589-93

24. Coronel ML, Chamorro N, Blanco I, et al. Medical and surgical management fo chronic thromboembolic pulmonary hypertension: a single center experience. Arch Bronconeumol 2014; 50:521-7.

25. Cannon JE, Su L, Kiely DG, et al. Dynamic risk stratification of patient long-term outcome after pulmonary endarterectomy: results from the United Kingdom National Cohort. Circulation 2016; 133:1761-71.

26. Ogawa A, Matsubara H. Balloon pulmonary angioplasty: a treatment option for inoperable patients with chronic thromboembolic pulmonary hypertension. Front Cardiovasc Med 2015; 2:4.

27. Mitsakis $P$, Yerly $P$, Dunet $V$, et al. Effects of endothelin receptor antagonist (ERA) bosentan on myocardial glucose metabolism in pulmonary arterial hypertension (PAH) and chronic thromboembolic pulmonary hypertension (CTEPH). Eur
Respir J 2017; 50:PA2414.

28. Lee YH, Song GG. Meta-analysis of randomized controlled trials of bosentan for treatment of pulmonary arterial hypertension. Korean J Intern Med 2013; 28:701-7.

29. Gall H, Hoeper MM, Richter MJ, et al. An epidemiological analysis of the burden of chronic thromboembolic pulmonary hypertension in the USA, Europe and Japan. Eur Respir Rev 2017; 26. pii:160121.

30. Jamieson SW, Kapelanski DP, Sakakibara N, et al. Pulmonary endarterectomy: experience and lessons learned in 1,500 cases. Ann Thorac Surg 2003; 76:1457-64.

31. Mayer E, Jenkins D, Lindner J, et al. Surgical management and outcome of patients with chronic thromboembolic pulmonary hypertension: results from an international prospective registry. J Thorac Cardiovasc Surg 2011; 141:702-10.

32. Galiè N, Ghofrani HA, Torbicki A, et al; Sildenafil Use in Pulmonary Arterial Hypertension (SUPER) Study Group. Sildenafil citrate therapy for pulmonary arterial hypertension. N Engl J Med 2005; 353:2148-57.

33. Tanabe N, Sugiura T, Tatsumi K. Recent progress in the diagnosis and management of chronic thromboembolic pulmonary hypertension. Respir Investig 2013; 51:134-46.

34. Voorburg JA, Cats VM, Buis B, Bruschke AV. Balloon angioplasty in the treatment of pulmonary hypertension caused by pulmonary embolism. Chest 1988; 94:1249-53

35. Jenkins D. New interventions to treat chronic thromboembolic pulmonary hypertension. Heart 2018; 104:1480-3.

36. van Es N, Coppens M, Schulman S, Middeldorp S, Buller HR. Direct oral anticoagulants compared with vitamin $\mathrm{K}$ antagonists for acute venous thromboembolism: evidence from phase 3 trials. Blood 2014; 124:1968-75.

37. Preston IR, Farber HW. Anti-coagulation in pulmonary arterial hypertension: the real blood and guts. J Thorac Dis 2016; 8:E1106-7.

38. Aoki T, Sugimura K, Tatebe $S$, et al. Comprehensive evaluation of the effectiveness and safety of balloon pulmonary angioplasty for inoperable chronic thrombo-embolic pulmonary hypertension: long-term effects and procedurerelated complications. Eur Heart J 2017; 38:3152-9.

39. Andreassen AK, Ragnarsson A, Gude E, Geiran O, Andersen R. Balloon pulmonary angioplasty in patients with inoperable chronic thromboembolic pulmonary hypertension. Heart 2013; 99:1415-20.

40. Hosokawa K, Abe K, Oi K, et al. Balloon pulmonary angioplasty-related complications and therapeutic strategy in patients with chronic thromboembolic pulmonary hypertension. Int J Cardiol 2015; 197:224-6.

41. Suntharalingam J, Treacy CM, Doughty NJ, et al. Long-term use of sildenafil in inoperable chronic thromboembolic pulmonary hypertension. Chest 2008; 134:229-36.

42. Kuznetsov MR, Reshetov IV, Orlov BB, et al. [Predictors of chronic thromboembolic pulmonary hypertension]. Kardiologiia 2018; 58:60-5. Russian.

43. Jeong I, Fernandes T, Alotaibi M, Kim NH. Direct oral anticoagulant use and thrombus detection in patients with chronic thromboembolic pulmonary hypertension referred for pulmonary thromboendarterectomy. Eur Respir J 2019; 54:OA5161.

44. Hayashi H, Tsuji A, Ueda J, et al. Comparison of efficacy and safety between direct oral anticoagulant and warfarin in patients with chronic thromboembolic pulmonary hypertension. Circulation 2018; 138(Suppl 1):A15733.

45. Bunclark K, Newnham M, Chiu YD, et al. A multicenter study of anticoagulation in operable chronic thromboembolic pulmonary hypertension. J Thromb Haemost 2020; 18:114-22.

46. Gavilanes-Oleas FA, Alves JL Jr, Fernandes CJC, et al. Use of direct oral anticoagulants for chronic thromboembolic pulmonary hypertension. Clinics (Sao Paulo) 2018; 73:e216.

47. Southwood M, MacKenzie Ross RV, Kuc RE, et al. Endothelin ETA receptors predominate in chronic thromboembolic pulmonary hypertension. Life Sci 2016; 159:104-10.

48. Skoro-Sajer N, Bonderman D, Wiesbauer F, et al. Treprostinil for severe inoperable chronic thromboembolic pulmonary hypertension. J Thromb Haemost 2007; 5:483-9.

49. Ghofrani HA, Hoeper MM, Halank M, et al. Riociguat for chronic thromboembolic pulmonary hypertension and pulmonary arterial hypertension: a phase II study. Eur Respir J 2010; 36:792-9.

50. Ghofrani HA, Simonneau G, D'Armini AM, et al; MERIT study investigators. Macitentan for the treatment of inoperable chronic thromboembolic pulmonary hypertension (MERIT-1): results from the multicentre, phase 2, randomised, double-blind, placebo-controlled study. Lancet Respir Med 2017; 5:785-94.

51. Halank M, Hoeper MM, Ghofrani HA, et al. Riociguat for pulmonary arterial hypertension and chronic thromboembolic pulmonary hypertension: results from a phase II long-term extension study. Respir Med 2017; 128:50-6.

52. Channick RN, Sitbon O, Barst RJ, Manes A, Rubin LJ. Endothelin receptor antagonists in pulmonary arterial hypertension. J Am Coll Cardiol 2004; 43(12 Suppl S):62S-67S

53. Ghofrani HA, D'Armini AM, Grimminger F, et al; CHEST-1 Study Group. Riociguat for the treatment of chronic thromboembolic pulmonary hypertension. N Engl J Med 2013; 369:319-29

54. Simonneau G, D'Armini AM, Ghofrani HA, et al. Riociguat for the treatment of 
chronic thromboembolic pulmonary hypertension: a long-term extension study (CHEST-2). Eur Respir J 2015; 45:1293-302.

55. Escribano-Subias P, Bendjenana H, Curtis PS, Lang I, Noordegraaf AV. Ambrisentan for treatment of inoperable chronic thromboembolic pulmonary hypertension (CTEPH). Pulm Circ 2019; 9:2045894019846433.

56. Jais X, D'Armini AM, Jansa P, et al. Bosentan for treatment of inoperable chronic thromboembolic pulmonary hypertension: BENEFiT (Bosentan Effects in iNopErable Forms of chronlc Thromboembolic pulmonary hypertension), a randomized, placebo-controlled trial. J Am Coll Cardiol 2008; 52:2127-34.

57. Ghofrani HA, Galiè N, Grimminger F, et al; PATENT-1 Study Group. Riocigua for the treatment of pulmonary arterial hypertension. N Engl J Med 2013 369:330-40.
58. Tiede H, Hoeper MM, Richter M, et al. Global burden of chronic thromboembolic pulmonary hypertension (CTEPH): an epidemiological analysis. Eur Respir J 2014; 44:P2326

59. Darocha S, Banaszkiewicz M, Pietrasik A et al. Sequential treatment with sildenafil and riociguat in patients with persistent or inoperable chronic thromboembolic pulmonary hypertension improves functional class and pulmonary hemodynamics. Int J Cardiol 2018; 269:283-8.

60. Puengpapat S, Pirompanich P. Incidence of chronic thromboembolic pulmonary hypertension in Thammasat University Hospital. Lung India 2018; 35:373-8.

61. Yu Y, Yang L, Zhang Y, et al. Incidence and risk factors of chronic thromboembolic pulmonary hypertension in patients with diagnosis of pulmonary embolism for the first time in real world. Clin Respir J 2018; 12:2551-8. 